Cipango Cahiers d'études japonaises

Hors-série | 2008

Autour du Genji monogatari

\title{
Suma, à la croisée du lyrisme et du destin
}

Suma, at the crossing of Lyricism and Fate

\section{Hirohiko Takada}

Traducteur : Estelle Leggeri-Bauer

\section{(2) OpenEdition}

\section{Journals}

Édition électronique

URL : https://journals.openedition.org/cipango/589

DOI : 10.4000/cipango.589

ISSN : 2260-7706

\section{Éditeur}

INALCO

Édition imprimée

Date de publication : 1 janvier 2008

Pagination : 41-68

ISBN : 978-2-85831-170-5

ISSN : $1164-5857$

\section{Référence électronique}

Hirohiko Takada, «Suma, à la croisée du lyrisme et du destin », Cipango [En ligne], Hors-série | 2008,

mis en ligne le 19 décembre 2012, consulté le 30 juin 2021. URL : http://journals.openedition.org/ cipango/589; DOI : https://doi.org/10.4000/cipango.589

Ce document a été généré automatiquement le 30 juin 2021.

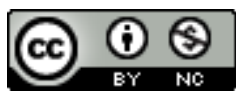

Cipango est mis à disposition selon les termes de la Licence Creative Commons Attribution - Pas d'Utilisation Commerciale 4.0 International. 


\title{
Suma, à la croisée du lyrisme et du destin
}

Suma, at the crossing of Lyricism and Fate

\author{
Hirohiko Takada
}

Traduction : Estelle Leggeri-Bauer

1 Suma est l'un des chapitres du Genji monogatari les plus intensément lyriques, et c'est certainement pour cette raison qu'il fait partie depuis longtemps des passages préférés des lecteurs. Le prince, qui a pris de lui-même l'initiative de son séjour à Suma sans attendre d'être accusé de rébellion contre l'autorité impériale, prend congé de ses proches, puis, sur place, mène une existence équivalant à celle d'un exilé, au cours de laquelle il partage sa tristesse avec ceux qui l'ont accompagné ${ }^{1}$. La partie se déroulant à Suma même débute au printemps, mais c'est surtout à partir de l'automne que la mélancolie envahit les paysages: l'auteur du roman développe alors un mode de description caractéristique faisant concorder les sentiments des personnages et leur environnement. La puissance d'émotion qui jaillit ainsi à l'automne pourrait être à l'origine de la légende entourant la genèse du chapitre selon laquelle Murasaki Shikibu aurait trouvé son inspiration en contemplant depuis le monastère Ishiyama où elle faisait retraite la lune se reflétant sur le lac Biwa, une nuit du $15^{\mathrm{e}}$ jour du $8^{\mathrm{e}}$ mois (c'està-dire au début de l'automne).

2 Le lyrisme de ce chapitre naît de la situation dans laquelle se trouve le héros : celui-ci s'est rendu en un lieu éloigné de la capitale, où il n'aurait jamais dû séjourner. Mais cette situation n'a pas que des implications poétiques. Suma est en effet le moment du Roman du Genji où le destin du héros se révèle. Si le Genji a quitté la capitale pour couper court à tout soupçon de rébellion, son départ obéit en réalité à une raison plus fondamentale encore : il souhaite ainsi préserver le statut de prince héritier de son fils adultérin né entre lui et Fujitsubo ${ }^{2}$. Le petit prince, rejeton du couple idéal, doit à tout prix être protégé, au-delà de la faute commise. La « descente à Suma » est ainsi un acte sacrificiel accompli par un homme dont c'est le destin et qui, en tant que héros de roman, ne peut y échapper. Ce destin passera par les souffrances du séjour à Suma et 
prendra un tour dynamique au chapitre suivant, lors de la rencontre avec la famille dite d'Akashi, le retour à la capitale et le recouvrement de la splendeur d'antan.

L'auteur poursuit ainsi une double entreprise, celle de faire partager au lecteur les sentiments de ses personnages à travers un lyrisme d'une grande intensité émotionnelle et celle de lui révéler la haute destinée de son héros. Pourtant, ces deux intentions sont quelque peu contradictoires du point de vue de la narration. La dimension lyrique dont l'une des conséquences est la multiplication des poèmes, a pour effet de suspendre l'écoulement du temps du récit, ou, à tout le moins, de le ralentir considérablement. D'un autre côté, la révélation du destin du héros prend place au sein d'une succession concrète d'actions et, de ce fait, aurait plutôt tendance à en accélérer la temporalité. On peut donc se demander comment ces deux dimensions essentielles s'entremêlent et structurent Suma tout à la fois. C'est ce à quoi nous allons tenter de répondre dans cet article.

Avant d'entrer dans le vif du sujet précisons un point. La question du destin du Genji est l'un des axes directeurs du roman-fleuve. Réfléchir sur cette question revient donc finalement à prendre le parti d'interroger la structure générale du Genji monogatari. Cet article, qui se borne à ne traiter que d'un chapitre, fait ainsi partie d'un projet de recherche plus ambitieux dont l'objet est d'explorer comment la structure générale du roman et sa dimension lyrique s'articulent l'une à l'autre.

\section{Les crimes du Genji et le poids de ses vies antérieures}

5 Le chapitre Suma commence avec la prise de décision, par le Genji, de se rendre dans la région éponyme. La série de scènes décrivant ses adieux aux gens de la maison du ministre de Gauche, à Murasaki no Ue, à Hana Chirusato, à Oborozukiyo ou encore à Fujitsubo, sont l'occasion pour le héros d'exprimer son déchirement de devoir les quitter. Les conversations successives font apparaitre un homme conscient de ses crimes, tout en annonçant déjà les modalités du développement ultérieur du récit : ses crimes doivent être compris comme le produit d'actes commis dans ses vies antérieures, ce qui revient à les présenter comme déterminés par le destin. Il convient donc d'examiner la signification de la « descente à Suma » du point de vue des actes du Genji, qui relèvent de sa vie présente, et du point de vue de la conscience qu'il a de devoir aussi porter le poids de ses existences antérieures.

Des deux crimes commis, le premier est resté à l'état de soupçon. Le Genji a en effet préféré quitter de lui-même la capitale avant même que son complot supposé contre l'empereur ne soit reconnu comme tel. Mais le fait que son existence à Suma s'apparente à un exil laisse à penser qu'il cherche ainsi à subir volontairement un châtiment pour le second crime, celui de l'adultère qui, lui, n'a pas été divulgué. On peut comparer à ce propos deux passages qui témoignent bien de ces deux aspects. Le premier passage est tiré d'une conversation du Genji à la veille de son départ pour Suma. Il s'adresse au père de sa défunte épouse Aoi, ministre de Gauche qui s'était retiré de la sphère politique après la mort de l'empereur Kiritsubo. Voici ce que dit le Genji :

Qu'il nous advienne ceci, qu'il nous advienne cela, tout est rétribution d'une vie antérieure: si nous partons de ce principe, nous ne pouvons nous en prendre qu'à nous-même. Quelqu'un qui, comme moi, sans qu'il soit pour cela relevé de ses rangs et titre, encourt la disgrâce de la Cour, fût-ce sous un prétexte futile, commettrait une faute grave, de l'aveu même de ceux de 
l'autre Empire, s'il continuait de se répandre partout au grand jour. Si l'on est résolu à m'envoyer en un lointain exil, ce doit être, certes, en châtiment de quelque crime abominable! Continuer à vivre comme si de rien n'était, en me fiant à ma conviction d'être sans reproche, serait aller au-devant de bien des avanies, et c'est pourquoi j'ai décidé de fuir ce monde plutôt que de m'exposer à des humiliations plus graves encore. ${ }^{3}$

「とあることもかかることも、前の世の報いにこそはべるなれば、言ひもてゆ けば、ただみづからのおこたりになむはべる。さしてかく官爵をとられず、あ さはかなることにかかづらひてだに、公のかしこまりなる人の、うつしざまに て世の中にあり経るは、各重きわざに外国にもしはべるなるを、遠く放ちつか はすべき定めなどもはべなるは、さまことなる罪に当たるべきにこそはべるな れ。濁りなき心にまかせてつれなく過ぐしはべらむもいと憚り多く、これより 大きなる恥にのぞまぬさきに世をのがれなむと思うたまへ立ちぬる」など、こ まやかに聞こえたまふ。

Le second passage est extrait de la brève rencontre entre Fujitsubo et le Genji, quelques jours après la scène précédente :

[Le Genji] se reprit [...] et se contenta [...] de dire :

- À la disgrâce imprévue qui me frappe, je n'ai, à la réflexion, trouvé qu'une seule explication, et elle me terrifie! Peu importe que je disparaisse pourvu que le Prince, un jour, règne sans encombre!

「かく思ひかけぬ罪に当たりはべるも、思うたまへあはすることの一ふしにな む、空も恐ろしうはべる。惜しげなき身は亡きになしても、宮の御世だに事な くおはしまさば」とのみきこえたまふぞことわりなるや。

7 Dans le premier extrait, le Genji explique avoir été démis de ses fonctions à la cour et récuse toute intention de trahir l'empereur, mais il préfère prendre les devants et s'en aller plutôt que courir le risque de se voir sévèrement accuser. Il se compare aux fonctionnaires qui ont été lourdement sanctionnés sans avoir pour autant perdu leur rang et leur titre, et il estime que lui ne pourra échapper à une lourde peine, car on lui a déjà retiré l'un et l'autre ${ }^{5}$, bien qu'aucune charge précise ne pèse sur lui à ce stade du récit. Face à son beau-père, le Genji avance comme explication le poids «des rétributions des vies antérieures ", tandis que, dans le second extrait, il attribue sa situation présente à la transgression que lui et Fujitsubo ont commis ensemble ("À la disgrâce imprévue qui me frappe, je n'ai, à la réflexion, trouvé qu'une seule explication, et elle me terrifie !»). Il est bien clair que le soupçon de félonie et les amours illicites ne sauraient avoir de liens directs. C'est précisément pour cela que l'auteur commence à filer le thème du destin, avec le poids de la vie antérieure, qui permet d'associer les deux crimes.

Lorsqu'il s'adresse à Fujitsubo, le Genji introduit un autre thème, celui du prince héritier dont le statut doit être à tout prix préservé. C'est son vœu le plus cher, comme il l'explique lui-même. Mais le plus intéressant est que la phrase qu'il prononce alors ( Peu importe que je disparaisse pourvu que le Prince, un jour, règne sans encombre !») ressemble à s'y méprendre à la description des sentiments de Fujitsubo peu après son entrée en religion, au chapitre Sakaki (L'arbre sacré) :

Elle-même [Fujitsubo] avait depuis longtemps renoncé en esprit à tous les biens de ce monde, mais les airs désemparés de ses serviteurs et la tristesse qui semblait les accabler avaient plus d'une fois ému son cœur, cependant que, faisant fi de son propre sort, seul la préoccupait le désir de voir un jour le Prince héritier régner en paix, et c'est dans cette intention qu'elle veillait à ce que les rites fussent ponctuellement accomplis. ${ }^{6}$

みなかねて思し棄ててし世なれど、宮人どもも拠りどころなげに悲しと思へる 気色どもにつけてぞ、御心動くをりをりあれど、わが身をなきになしても東宮 の御世をたひらかにおはしまさばとのみ思しつつ、御行ひたゆみなく勤めさせ たまふ 
Ce rapprochement montre que le Genji de Suma a évolué pour devenir un personnage dont les sentiments rejoignent désormais ceux de Fujitsubo. Cette nouvelle description des deux personnages, comme deux êtres identiques par leur nature et partageant une même sensibilité, souligne bien qu'ils étaient voués à vivre un même destin qui les a déjà conduits à commettre un crime redoutable.

10 Il convient toutefois de ne pas se méprendre sur la signification de leur crime. Dans le roman, la conscience qu'en ont les personnages est indissociablement liée à la nécessité d'en préserver le prince héritier. Il n'est donc pas de nature à être effacé par un simple châtiment ou par une simple expiation. Situé dans le contexte historique du Genji monogatari, ce crime aurait un caractère très nettement moral et, de plus, par l'atteinte qu'il porte à la lignée impériale, il serait d'une extrême gravité. Pourtant, le récit ne discute pas le crime en tant que tel, il le présente comme une nécessité du destin et place au premier plan la question de la préservation de son statut pour le prince héritier. Et tout se tient, même si l'on peut y voir une ironie du sort: aux chapitres précédents, l'empereur défunt, Kiritsubo, qui désespérait de ne pouvoir transmettre son trône au Genji son premier fils cadet, avait dissipé son amertume en reportant ce vœu si cher sur son dernier rejeton, devenu alors à ses yeux le prince idéal. Dans ce prolongement, avant de mourir, Kiritsubo a demandé instamment au nouvel empereur Suzaku (son fils aîné) de prendre le plus grand soin de ses deux frères. Au chapitre Suma, il s'avère que les dernières volontés de l'empereur défunt n'ont pas été respectées puisque la position du Genji à la cour s'est considérablement fragilisée. Il ne reste plus qu'une issue au héros, soupçonné de surcroît de félonie : empêcher coûte que coûte que le petit prince ne soit à son tour écarté.

11 À ce stade, on constate que le traitement accordé par le récit à la question du crime du Genji est entièrement conditionné par une autre question, celle de la sauvegarde du prince héritier. En effet, le Genji monogatari n'est pas un récit de faute et de rédemption. Il est d'ailleurs courant de dire à ce propos que le héros a une conscience bien faible de son crime. En fait, s'il est vrai que l'auteur ne l'a pas représenté en homme rongé par la souffrance que devrait lui valoir un face-à-face avec sa conscience, on ne peut nier que ce roman est l'histoire d'un idéal: idéal de l'accession au trône impérial du prince héritier, mais dont l'accomplissement nécessite que soient endurées les souffrances engendrées par le crime. L'ironie du destin qui fait de ce jeune garçon, dont la naissance est entachée par un acte effroyable, l'espoir sur lequel l'empereur retiré Kiritsubo lui-même fonde sa succession, est dès lors un motif essentiel irriguant le roman-fleuve. Ce motif est d'ailleurs associé très tôt au destin du Genji. Il apparaît dès le chapitre Waka-murasaki (Jeune Grémil), dans un passage se déroulant quelque temps après sa relation adultère avec Fujitsubo. Ayant fait un rêve étrange, le héros en demande une explication à un devin et apprend presque concomitamment qu'elle est enceinte. Ce passage annonce en filigrane la descente à Suma.

Sire le Commandant [le Genji], quant à lui, eut un songe effroyable et bizarre; il convoqua un interprète, et quand il l'interrogea, celui proposa une explication impossible et incroyable.

- Il y a là-dedans des événements fâcheux qui vous imposeront une réclusion. Cette observation le troubla et il déclara:

- Ce n'est pas moi qui ai eu ce songe, c'est celui d'un autre que je vous ai rapporté. Ne parlez à personne de votre interprétation!

Et tandis qu'à part soi il se demandait de quoi il pouvait bien s'agir, il apprit l'état de la Princesse [Fujitsubo]; il fit le rapprochement : et si par aventure, c'était cela? Alors le désir de la voir le reprit, plus violent, mais il eut beau user des arguments les plus pressants, la 
Myōbu, tout bien considéré, estima, fort inquiète que les difficulté croissantes rendaient désormais son entremise impossible. Les réponses, évasives, en une ligne, qu'il obtenait naguère à grand-peine, avaient totalement cessé.?

中将の君も、おどろおどろしうさま異なる夢を見たまひて、合はする者を召し て問はせたまへば、及びなう思しもかけぬ筋のことを合はせけり。「その中に 違ひ目ありて、つつしませたまふべきことなむはべる」と言ふに、おづらはし

くおぼえて、「みづからの夢にはあらず、人の御事を語るなり。この夢合ふま

で、また人にまねぶな」とのたまひて、心の中には、いかなることならむと思 しわたるに、この女宮の御事聞きたまひて、もしさるやうもやと思しあはせた まふに、いとどしくいみじき言の葉尽くし聞こえたまへど、命婦も思ふに、い とむくつけうわづらはしさまさりて、さらにたばかるべき方なし。はかなき一 行の御返りのたまさかなりしも絶えはてにたり。

Nul épisode précédant le départ pour Suma ne décrit un Genji se remémorant l'interprétation de son rêve, mais il ne fait aucun doute que celle-ci s'est vérifiée. Le roman traite en surimpression les deux crimes : d'une part, une intention supposée de trahir l'empereur Suzaku, mais qui n'a, en fait, aucun fondement et, d'autre part, un véritable acte de trahison envers la lignée impériale avec l'admission au titre d'héritier au trône d'un garçonnet né d'une liaison illicite avec une concubine impériale. Mais si on examine les choses autrement, en les replaçant dans le contexte historique du milieu de l'époque de Heian, la donne diffère considérablement: le prince héritier et son protecteur le Genji n'ont plus aucune assise politique depuis que l'empereur retiré Kiritsubo est mort et que Fujitsubo est entrée en religion. Ils ne constituent donc plus une menace sérieuse pour le clan de la dame du Kokiden, mère de l'empereur Suzaku8. Il faut toutefois tenir compte du fait que le personnage de roman qu'est le Genji est, depuis sa plus tendre enfance, d'une étoffe bien supérieure à son frère aîné (l'empereur Suzaku) et qu'il inspire encore une nette antipathie à la dame du Kokiden. Il est clair par ailleurs que la seule liaison entre le Genji et Oborozukiyo n'aurait pas pu être qualifiée d'acte de rébellion politique, même si la jeune fille était promise à l'empereur'. Mais l'auteur du roman savait pertinemment que, dans la vie réelle comme dans la fiction, les accusations de trahison reposent moins sur des agissements particuliers que sur des prétextes. Murasaki Shikibu a ainsi joué sur une construction narrative à deux niveaux : sur le devant de la scène, elle a placé une soi-disant trahison, mais dans le fond, elle a inventé un véritable crime de trahison avec la personne du prince héritier. Et elle a réussi à utiliser l'idée du destin inéluctable conduisant au crime pour relier le rêve caressé par l'empereur Kiritsubo d'abdiquer en faveur du Genji et l'avènement du jeune prince.

Le destin du Genji prendra un autre tour quand il rencontrera la famille d'Akashi, lors de son séjour à Suma, comme nous le verrons plus loin.

\section{Le lyrisme du chapitre Suma}

On l'a déjà dit, le chapitre Suma abonde en passages à caractère lyrique, que l'on songe aux scènes de séparations avant le départ pour l'exil ou aux échanges épistolaires avec les proches restés à la capitale. Toutefois, c'est surtout dans la partie du chapitre se déroulant au cours de l'automne et jusqu'au début de l'hiver que ces passages se concentrent. La mélancolie qui imprègne la saison d'automne sert de toile de fond à un changement de ton très net. L'un des passages les plus fameux en témoigne bien :

À Suma, au vent d'automne qui accable les esprits, encore que la mer fût assez éloignée,

des vagues du rivage soulevées par ce vent dont Yukihira le Moyen Conseiller disait 
que "le souffle franchit la barrière", nuit après nuit, le bruit en vérité sonnait tout proche, et rien n'était mélancolique autant que l'automne en pareil lieu. Dans le silence de la nuit, car bien peu nombreux étaient ceux qui l'entouraient, seul éveillé quand il souleva la tête pour entendre l'ouragan qui faisait rage aux quatre horizons, il eut le sentiment que les vagues déferlaient à son chevet, et sans qu'il en eût conscience, ses larmes coulaient à faire chavirer son appuie-tête. Il pinça la cithare, et les quelques accords que, pourtant il en tirait lui-même rendaient un son si lugubre qu'il les interrompit :

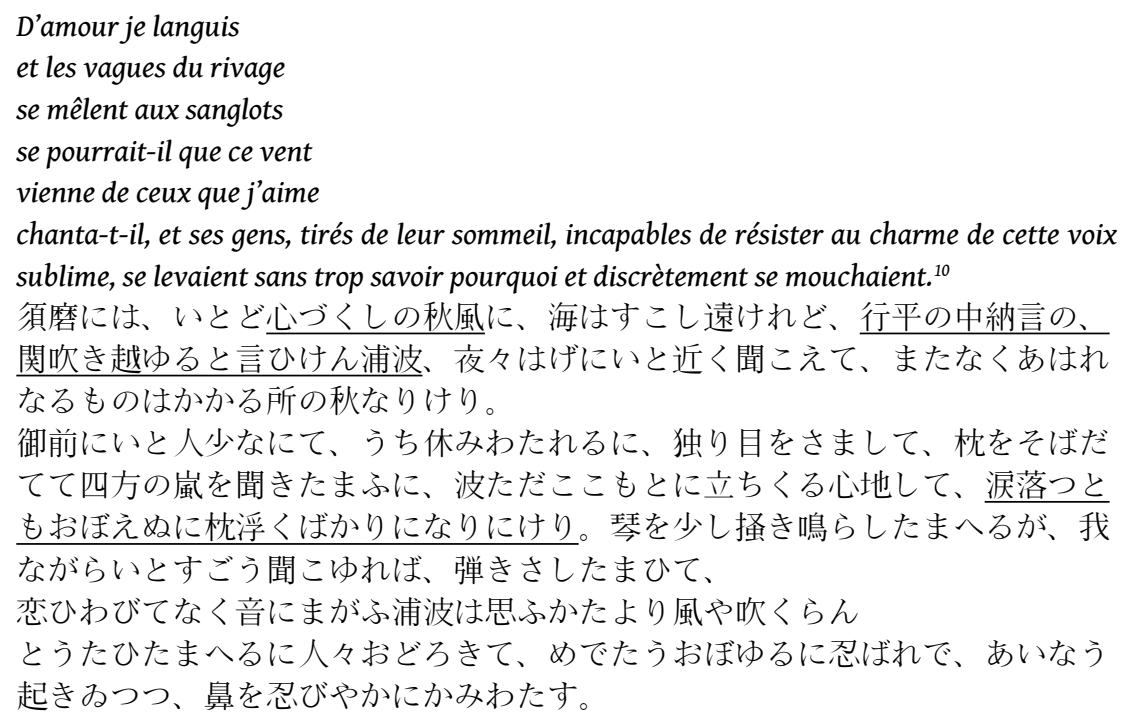

La description de cette scène nocturne s'appuie uniquement sur des données sonores. Le bruit du vent et celui des vagues sont cités à trois reprises en contiguïté, mais toujours sous des espèces différentes: le "vent d'automne qui accable les esprits " (kokorozukushi no akikaze) est associé aux "vagues du rivage » (uranami), l'« ouragan qui faisait rage aux quatre horizons " (yomo no arashi) aux « vagues » (nami) et, enfin, dans le poème composé par le Genji, les «vagues du rivage " réapparaissent à côté du «vent » (kaze). La dernière occurrence, particulièrement remarquable, a donné lieu à diverses interprétations. Les "vagues» sont précédées, dans le texte original, de l'expression «bruit de sanglots » (naku ne). Littéralement, le poème dit : « les vagues du rivage qui ressemblent (magau) à des sanglots ». D'aucuns ont attribué ces sanglots au Genji, d'autres y ont entendu les pleurs des gens de la capitale. Nous suivons la première interprétation. Le plus intéressant dans ce poème est la façon dont son auteur combine ces bruits à la provenance hypothétique du vent, définie par "ceux que j'aime ", c'est-à-dire la capitale, ce qui donne littéralement : " les vagues du rivage que je prends pour un bruit de sanglots, serait-ce le vent qui souffle depuis ceux que j'aime [la capitale]?" Par ces différents sons se faisant écho, le waka s'enrichit d'une profondeur particulière. Et dans le prolongement du poème, son écoute fait pleurer les gens du Genji. Murasaki Shikibu a ainsi joué sur la répétition d'expressions similaires pour étoffer, strate par strate, le paysage sonore de son roman et les sentiments de ses personnages.

Le lyrisme de ce passage ne repose pas seulement sur les alliances poétiques faisant concorder sentiments des personnages et leur environnement, il se révèle également dans le recours au procédé classique de la citation de poèmes. Maints extraits de waka et de kanshi interviennent ainsi au sein du chapitre pour dire le caractère isolé et la grande modestie de la nouvelle résidence du Genji, ce qui rend les descriptions 
particulièrement prenantes. Dans le passage précédemment cité, le « vent d'automne qui accable les esprits » (souligné par une ligne continue) renvoie au poème suivant :

\begin{tabular}{|l|l|}
\hline $\begin{array}{l}\text { 木の間より } \\
\text { Ko no ma yori }\end{array}$ & À travers les arbres \\
\hline $\begin{array}{l}\text { もりくる月の } \\
\text { Morikuru tsuki no }\end{array}$ & S'infiltre la lune \\
\hline $\begin{array}{l}\text { 影見れば } \\
\text { Kage mireba }\end{array}$ & À la vue de sa clarté \\
\hline $\begin{array}{l}\text { 心づくしの } \\
\text { Kokoro zukushi no }\end{array}$ & L'automne, qui accable les esprits \\
\hline $\begin{array}{l}\text { 秋は来にけり } \\
\text { Aki wa kinikeri }\end{array}$ & Est bien arrivé \\
\hline $\begin{array}{l}\text { Anonyme } \\
\text { Kokin shū (Recueil de poèmes anciens et modernes) } \\
\text { «Automne », 1 }\end{array}$ \\
\hline
\end{tabular}

17 Et le passage "sans qu'il en eût conscience, ses larmes coulaient à faire chavirer son appuie-tête " pourrait se référer au poème suivant, dont l'expression «l'appuie-tête prêt à chavirer » (makura uku) est un lieu commun poétique pour dire la solitude d'une personne sur sa couche :

\begin{tabular}{|l|l|}
\hline $\begin{array}{l}\text { 独り寝の } \\
\text { Hitorine no }\end{array}$ & Sur mes larmes qui ruissellent \\
\hline $\begin{array}{l}\text { 床にたまれる } \\
\text { Tokoni tamareru }\end{array}$ & Dans le creux de mon lit \\
\hline $\begin{array}{l}\text { 淚には } \\
\text { Namida niwa }\end{array}$ & Où je me trouve seul \\
\hline $\begin{array}{l}\text { 石の枕も } \\
\text { Ishi no makura mo }\end{array}$ & Mon appuie-tête en pierre \\
\hline $\begin{array}{l}\text { 浮きぬべらなり } \\
\text { Ukinuberanari }\end{array}$ & Est prêt à chavirer \\
\hline $\begin{array}{l}\text { Anonyme } \\
\text { Kokin rokujō (Poèmes anciens et modernes en six livres) } \\
\text { Livre V, « appuie-tête », poème nº } 3241\end{array}$ \\
\hline
\end{tabular}

18 Le dernier point, certainement le plus complexe à examiner, est celui des personnages historiques ayant eux-mêmes vécu une expérience similaire à celle du Genji. Ces personnages nommément cités ou présents à travers des extraits de leurs poèmes se 
combinent au héros, qui, lui, relève entièrement de la fiction, pour, fait remarquable, retrouver partiellement vie à travers lui. Double paradoxe d'un être purement imaginaire et distinct de ses multiples modèles, qui naît pourtant d'une alliance avec des personnages historiques, et dont la construction, a contrario, permet précisément d'animer de nouveau ces hommes ayant réellement existé. C'est ce que nous allons voir à travers plusieurs figures historiques, le Moyen Conseiller Ariwara no Yukihira (818-893), puis le ministre Sugawara no Michizane (845-903) et le poète chinois Bai Juyi (772-846).

Trois poèmes peuvent être donnés comme sources de la phrase où il est question de Yukihira dans l'extrait cité plus haut. Le premier poème est précisément attribué au Moyen Conseiller :

\begin{tabular}{|l|l|}
\hline $\begin{array}{l}\text { 旅人は } \\
\text { Tabibito wa }\end{array}$ & Du voyageur \\
\hline $\begin{array}{l}\text { 袂涼しく } \\
\text { Tamoto suzushiku }\end{array}$ & Les manches \\
\hline $\begin{array}{l}\text { なりにけり } \\
\text { Narinikeri }\end{array}$ & Se sont refroidies \\
\hline $\begin{array}{l}\text { 関吹き越ゆる } \\
\text { Seki fuki koyuru }\end{array}$ & Du vent [provenant] du rivage de Suma \\
\hline $\begin{array}{l}\text { 須磨の浦風 } \\
\text { Suma no urakaze }\end{array}$ & Le souffle franchit la barrière \\
\hline $\begin{array}{l}\text { Moyen Conseiller Yukihira } \\
\text { Shoku Kokin shū } \\
\text { (Suite au Recueil de poèmes anciens et modernes) } \\
\text { « Voyage », poème no 868 }\end{array}$ \\
\hline
\end{tabular}

On y retrouve en effet l'expression «le souffle franchit la barrière » (seki fuki koyuru), explicitement citée par Murasaki Shikibu. C'est toutefois le poème suivant, composé par un autre poète, qui est le plus proche du passage par le sens :

\begin{tabular}{|l|l|}
\hline $\begin{array}{l}\text { 秋風の } \\
\text { Akikaze no }\end{array}$ & À chaque fois. \\
\hline $\begin{array}{l}\text { 関吹き越ゆる } \\
\text { Seki fukikoyuru }\end{array}$ & Que du vent d'automne \\
\hline $\begin{array}{l}\text { たびごとに } \\
\text { Tabigoto ni }\end{array}$ & Le souffle franchit la barrière \\
\hline $\begin{array}{l}\text { 声うちそふる } \\
\text { Koe uchisouru }\end{array}$ & Les vagues du rivage de Suma \\
\hline
\end{tabular}




\begin{tabular}{|l|l|}
\hline $\begin{array}{l}\text { 須磨の浦波 } \\
\text { Suma no uranami }\end{array}$ & Y ajoutent leur fracas \\
\hline $\begin{array}{l}\text { Mibu no Tadami } \\
\text { Shin Kokin shū } \\
\text { (Nouveau recueil de poèmes anciens et modernes) } \\
\text { « Divers », } 2^{\mathrm{e}} \text { partie, poème } \mathrm{n}^{\circ} 1599\end{array}$ \\
\hline
\end{tabular}

21 Il faut aussi tenir compte de ce troisième poème qui de toute évidence inspira la composition de Tadami :

\begin{tabular}{|l|l|}
\hline $\begin{array}{l}\text { 住の江の } \\
\text { Sumi no e no }\end{array}$ & À Suminoe \\
\hline $\begin{array}{l}\text { 松を秋風 } \\
\text { Matsu wo akikaze }\end{array}$ & Plus le vent d'automne \\
\hline $\begin{array}{l}\text { 吹くからに } \\
\text { Fuku kara ni }\end{array}$ & Souffle sur les pins \\
\hline $\begin{array}{l}\text { 声うちそふる } \\
\text { Koe uchisouru }\end{array}$ & Plus les vagues blanches au large \\
\hline $\begin{array}{l}\text { 沖つ白波 } \\
\text { Okitsu shiranami }\end{array}$ & Y ajoutent leur fracas \\
\hline $\begin{array}{l}\text { Ōshikōchi no Mitsune } \\
\text { Kokin shū, «Célébrations », poème no } 360\end{array}$ \\
\hline
\end{tabular}

Les deux premiers poèmes soulèvent, entre autres, la question de savoir pourquoi Murasaki Shikibu cite Yukihira alors même que le poème de Tadami est le plus proche de la situation décrite. On peut essayer de remplacer le nom d'un auteur par l'autre: «ce vent dont Tadami disait que le souffle franchit la barrière». Cette phrase, parfaitement juste du point de vue des sources poétiques possibles, ne provoquerait pourtant aucune émotion chez le lecteur et n'évoque en rien l'image d'une pauvre demeure. Déjà un peu plus haut dans le chapitre, peu après l'arrivée du Genji à Suma, Murasaki Shikibu avait planté le décor en se référant à Yukihira :

L'endroit où [le Genji] devait vivre était proche de l'habitation où Yukihira le Moyen Conseiller, " par l'onde amère trempée se morfondait » [...].1.

おはすべき所は、行平の中納言の藻塩たれつつわびける家居近きわたりなりけ り

23 Ce passage évoque un moment de la vie d'Ariwara no Yukihira, qui fut envoyé en exil à Suma ; il renvoie aussi, plus précisément, au poème suivant ${ }^{13}$ :

\begin{tabular}{|l|l|}
\hline $\begin{array}{l}\text { わらばに } \\
\text { Wakuraba ni }\end{array}$ & Si d'aventure \\
\hline
\end{tabular}




\begin{tabular}{|l|l|}
\hline $\begin{array}{l}\text { 問ふ人あらば } \\
\text { Tou hito araba }\end{array}$ & Des gens vous questionnent \\
\hline $\begin{array}{l}\text { 須磨の浦に } \\
\text { Suma no ura } n i\end{array}$ & Sans hésiter répondez: \\
\hline $\begin{array}{l}\text { 藻塭たれつつ } \\
\text { Moshio taretsutsu }\end{array}$ & Par l'onde amère trempée \\
\hline $\begin{array}{l}\text { わぶと答へよ } \\
\text { Wabu to kotaheyo }\end{array}$ & Il se morfond en le rivage de Suma \\
\hline $\begin{array}{l}\text { Moyen Conseiller Yukihira } \\
\text { Kokin shū, «Divers », } 2^{\mathrm{e}} \text { partie, poème } \mathrm{n}^{\circ} 962\end{array}$ \\
\hline
\end{tabular}

Le renvoi au personnage de Yukihira apparaît ainsi comme une nécessité intertextuelle évidente, mais cela n'empêche en rien de laisser planer un doute sur l'authenticité du poème supposé avoir inspiré le vers «le souffle franchit la barrière ». Le doute tient d'abord à la chronologie: le recueil dans lequel il figure, le Shoku kokin shū, est un ouvrage tardif, commandé en 1259, achevé en 1265, donc nettement postérieur au Shin kokin shū (début du XIII ${ }^{e}$ siècle), dans lequel figurait le poème de Tadami. À cela s'ajoute un autre argument, déjà avancé par l'auteur du Kaen rensho no kotogaki 歌苑連署事書 ${ }^{14}$ :

Le poème du Shoku kokin shū avec "Du vent [provenant] du rivage de Suma / Le souffle franchit la barrière " a été choisi par le seigneur Mitsutoshi ${ }^{15}$, mais il a été noté qu'il ne figure pas dans le recueil du Moyen Conseiller Yukihira ; ledit seigneur s'est donc appuyé sur le Roman du Genji [pour l'attribuer à Yukihira]; or, comme cette source est sujette à caution, c'est Mitsutoshi qui a endossé les soupçons. ${ }^{16}$

続古今の、関吹き越ゆるすまの浦風は、光俊朝臣選び入れて侍りける、行平中 納言の集にもなきよし沙汰ありけるに、かの朝臣は源氏の物語を証拠にひきけ れども、それもさはやかに首尾かける事もなければ光俊疑をおひにけり。

Ce texte peut être compris comme une critique larvée à l'endroit de Mitsutoshi qui s'était imposé de force à l'équipe chargée de la compilation du Shoku kokin shū, et dont le comportement a entaché par la suite le contenu de l'anthologie. Si finalement on ne connaîtra jamais le fond de l'affaire, il est clair qu'une telle discussion a pu se développer parce que rien ne permettait d'affirmer avec certitude que le vers cité dans le Genji monogatari provenait bien d'un poème de Yukihira. On en est réduit à penser qu'il existait, à l'époque de la composition du roman, un poème qui était peut-être celui du Shoku kokin shā, mais qui pouvait aussi bien être un poème lui ressemblant et à présent perdu.

D'autres exemples dans le roman évoquent le nom d'un personnage historique, mais laissent planer un doute sur le poème à lui associer. Que l'on songe à l'exemple suivant, tiré de la deuxième partie de Wakana (Jeunes herbes) et qui se déroule au cours d'un pèlerinage à Sumiyoshi :
À Suminoe
sur les pins à la minuit
givre déposé
est-ce parure de coton
que le dieu y attacha 
Elle [Murasaki] évoqua le matin de neige, qu'avait chanté Takamura no Ason en son poème: "le Mont Hira même..."; était-ce le signe que le dieu avait agréé la fête donnée en son honneur? se dit-elle, et sa foi en fut réconfortée. ${ }^{17}$

住の江の松に夜ぶかくおく霜は神のかけたる木綿㹄かも

篁朝臣の、「比良の山さへ」と言ひける雪の朝を思しやれば、祭の心うけたま

ふしるしにやと、いよいよ頼もしくなむ。

Dans cet exemple, l'auteur attribue à Ono no Takamura 小野筀 (802-852), un poème qui, selon le Fukuro zōshi 袋草紙 ${ }^{18}$, est de la main de Sugawara no Fumitoki 菅原文時 (899-981).

Sieur Fumitoki a composé:

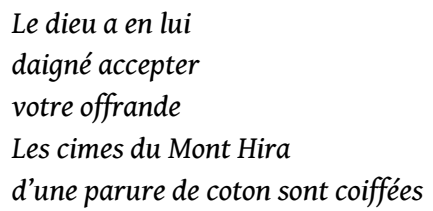

Shitagō demande: "Quelle est la source d'inspiration?» Et Fumitoki, de s'abstenir de répondre: «Comment, Seigneur Shitagō, vous ne le savez pas? " 文時卿云はく、

ひもろぎは神の心にうけつらん比良の高嶺ゆふかづらせり

順、問ひて云はく、「ゆ总、如何」と。文時、「順主は知らざりけりな」と

て、余の答へなしと云々。$$
\text { personnages historiques. La scène se déroule le } 15^{\mathrm{e}} \text { jour } \mathrm{du} 8^{\mathrm{e}} \text { mois et fait partie des }
$$
passages les plus célèbres du chapitre Suma.

Quand la lune se leva dans toute sa splendeur, le Prince [le Genji] se souvint que cette nuit était la quinzième, et il songea avec nostalgie aux concerts du Palais; et quand son imagination lui montra telle ou telle qui, ici ou là, devait être en train de la contempler, son regard se fixa sur la face de la lune:

\section{À deux mille lieues d'ici \\ le cour de mon ami}

murmura-t-il, et nul ne sut, une fois de plus, retenir ses larmes. Évoquant la Princesse religieuse [Fujitsubo] à l'instant qu'elle avait prononcé le vers: "le brouillard qui m'en sépare", il en éprouva un désir inexprimable de la revoir, et les souvenirs affluèrent, d'autres moments encore, si bien qu'il éclata en sanglots. 
Ses gens eurent beau lui faire observer que la nuit avançait, il ne pouvait se résoudre encore à rentrer.

\author{
Sa vue un instant \\ De mon ennui me distrait \\ Pour lointain que soit \\ De la lune le Palais \\ Des retrouvailles futures
}

Le souvenir mêlé de regrets lui revint alors de l'attitude de Sa Majesté [l'empereur Suzaku], cette nuit-là où Elle l'avait, avec tant d'aménité, entretenu des choses d'antan et de Sa ressemblance avec l'Empereur retiré:

Le vêtement dont

Sa Majesté me gratifia, à présent est ici

murmura-t-il, et il se retira. Il avait en effet conservé le vêtement reçu à cette occasion, et qui ne le quittait jamais.

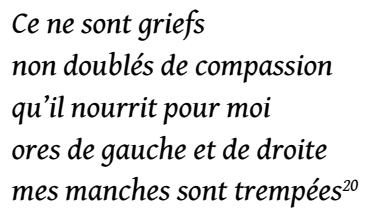

月のいとはなやかにさし出でたるに、今宵は十五夜なりけりと思し出でて、殿 上の御遊び恋しく、所どころながめたまふらむかしと、思ひやりたまふにつけ ても、月の顔のみまもら扎たまふ。「二千里外故人心」と誦じたまへる、例の 淚もとどめられず。入道の宮（藤壶）の、「霧やへだつる」とのたまはせしほ ど言はむ方なく恋しく、をりをりのこと思ひ出でたまふに、よよと泣かれたま ふ。「夜更けはべりぬ」と聞こゆれど、なほ入りたまはず。

見るほどでしばしなぐさむめぐりあはん月の都は遥かなれども

その夜、上（朱雀帝）のいとなつかしう昔物語などしたまひし御さまの、院に 似たてまつりたまへりしも恋しく思ひ出できこえたまひて、「恩賜の御衣は今

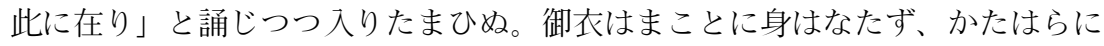
置きたまへり。

うしとのみひとへにものは思ほえでひだりみぎにもぬるる袖かな Michizane. Ces deux évocations font jaillir l'image de l'adversité que les deux grands hommes ont rencontrée dans leur vie. Le poème de Bai Juyi a été composé à l'époque où son ami Yuan Zhen 元槙 (jap. Genshin), fonctionnaire disgracié, avait été envoyé en poste à Jiangling, loin de la capitale.

Une nuit du 15 jour du 8e mois, de service au Palais, je suis seul; tourné vers la lune, je pense à Yuan Zhen.

Les tours d'or et d'argent s'enfoncent dans la nuit

Seul au Bureau, je passe la nuit et pense à vous

Beauté de l'astre pur, en cette soirée du quinze

À deux mille lieues d'ici, le cœur de mon ami

À l'Orient du Palais sur la rive, l'onde vaporeuse, glacée

Au Ponant, la Salle des Bains dont la clepsydre [retentit], profonde

Je crains que nous ne contemplions la même pure clarté

À Jiangling, [terre] basse et humide, l'automne est fort brumeux ${ }^{21}$.

Hakushi bunshū

(Collection des œuvres de Bai Juyi), vol. 14 


\begin{tabular}{|c|c|}
\hline $\begin{array}{l}\text { 八月十五日夜 禁中独直 } \\
\text { 銀台金闕夕べに沈々 } \\
\text { 独宿相い思うて翰林に在り } \\
\text { 三五夜中新月の色 } \\
\text { 二千里外故人の心 } \\
\text { 渚宮の東面煙波は冷ややかに } \\
\text { 浴殿の西頭鐘漏は深し } \\
\text { 猶ほ恐る清光を同じく見ざるを } \\
\text { 江陵は卑湿にして秋陰足し }\end{array}$ & $\begin{array}{l}\text { 対月憶元九 } \\
\text { 銀台金闕夕ベに沈々 } \\
\text { 独宿相思在翰林 } \\
\text { 三五夜中新月色 } \\
\text { 二千里外故人心 } \\
\text { 渚宮東面煙波冷 } \\
\text { 浴殿西頭鐘漏深 } \\
\text { 猶恐清光不同見 } \\
\text { 江陵卑湿秋陰足 }\end{array}$ \\
\hline \multicolumn{2}{|c|}{$\begin{array}{l}\text { (『白氏文集』巻 } 14 \text { 「八月十五夜、 } \\
\text { 禁中に独り直し、月に対して元九（元槙を憶う」） }\end{array}$} \\
\hline
\end{tabular}

Ce poème n'a pas été composé lors d'un exil du poète lui-même, mais il traite de ce thème (il songe à son ami loin de lui) et doit être mis en parallèle avec d'autres citations de poèmes de Bai Juyi dans Suma, qui se réfèrent au propre exil du grand poète ${ }^{22}$. Le poème en chinois de Michizane cité dans le même passage a été composé à Dazaifu et est certainement l'une de ses plus célèbres compositions :

L'an dernier à la même heure nocturne, je me tenais au Pavillon de Pureté et de Fraîcheur

Sur «Mélancolie d'automne ", je filais des vers déchirants de solitude

Le vêtement dont Sa Majesté me gratifia, à présent est ici

Jour après jour, respectueusement, je le découvre et en respire le parfum

Kanke kōshū (Recueil postérieur de Sugawara)

Dixième jour du neuvième mois, $n^{\circ} 482$

\begin{tabular}{|l|l|}
\hline 去年の今夜清凉に侍す & 去年今夜侍清凉 \\
秋思の詩揙独り断腸 & 秋思詩篇独断腸 \\
恩賜の御衣は今此在り & 恩賜御衣今在此 \\
捧げ持ちて每日余香を拝す & 捧持毎日拝余香 \\
\hline
\end{tabular}

Le poème renvoie à un épisode de l'exil de Michizane où le ministre déploie un vêtement offert par l'empereur avant son départ, vêtement qui lui rappelle la cour ${ }^{23}$. Par association d'idées, l'allusion au poème de Michizane installe ainsi, au cœur du chapitre Suma, l'image du grand ministre disgracié que le désespoir voue à la mort loin de la capitale. Pour le protagoniste du roman, le désir des "retrouvailles du Palais " n'en est que plus impérieux. Pour le lecteur, d'autres scènes renforcent l'assimilation des deux personnages: la chute d'éclairs ${ }^{24}$ ou encore l'apparition de l'esprit de l'empereur retiré Kiritsubo ${ }^{25}$. Michizane s'avère ainsi être le personnage historique le plus proche du Genji ce qui laisse présager, à ce stade du récit, qu'un destin tragique est réservé au héros. Or la comparaison s'arrête là. Car toute l'habileté de Murasaki Shikibu repose sur un effet de retournement: la proximité avec Michizane qu'elle a créée au chapitre Suma est finalement récusée aux chapitres suivants, lorsqu'elle fait vivre à son personnage une destinée qui l'en éloigne radicalement. Mais on retiendra de cela qu'en forgeant ainsi l'image d'un personnage touchant et pathétique grâce aux citations de poèmes de Michizane, l'auteur fait preuve d'une forte compassion pour ce dernier. Cela tient peut-être à l'environnement familial dans lequel Murasaki Shikibu a été élevée, avec un père lettré au cursus honorum finalement limité. Elle ne pouvait donc que jeter un regard bienveillant sur la vie de Michizane qui, quoique grand lettré, fut emporté dans les tourments de la politique. Cette compassion que Murasaki Shikibu porte à titre personnel au ministre disgracié laisse entrevoir un aspect de la personnalité de la « romancière » qui, insatiable, puise son inspiration créatrice à toutes les sources. 


\section{À la croisée du destin et du lyrisme}

vient de voir comment les scènes lyriques évoquaient avec beaucoup d'émotion l'isolement du Genji et la modestie de son lieu de vie: la profusion de citations poétiques, les compositions du prince lui-même ou de ses compagnons d'infortune, qui en dressent le portrait, éveillent inexorablement l'empathie du lecteur pour ce récit de relégation. Mais la portée du lyrisme ne saurait être réduite aux seules scènes qui le font naître. Celui-ci joue un rôle plus ambitieux au sein du Roman du Genji: la mélancolie profonde confinant au désespoir est une façon de mettre en pleine lumière le caractère hors norme du personnage principal. On peut ainsi considérer que les scènes lyriques portent sans faillir l'autre thème du chapitre : la révélation du destin du héros, dont nous avons déjà parlé plus haut. Ce point apparaît nettement au tournant de Suma et d'Akashi, où l'histoire progresse au gré de phénomènes surnaturels dont l'occurrence est d'ailleurs très rare au sein du Roman du Genji. Or il est frappant de constater que ces scènes fantastiques ne sont en aucun cas inconsistantes face aux passages lyriques. Bien au contraire, ces derniers étaient une condition nécessaire, une sorte de grande mise en scène indispensable à leur bon déploiement. On peut donc se demander en quoi ces scènes lyriques qui, à première vue, s'opposent à la dynamique du récit, sont en fait partie prenante du développement narratif dans son ensemble.

Nous avons déjà dit que les scènes lyriques, par définition, ralentissaient la progression de la narration. Or, dans le chapitre Suma, cette modification du rythme coïncide avec l'interruption quasi totale des échanges épistolaires (la dame du Kokiden, qui a eu vent de l'existence raffinée des exilés, redouble de vigilance, ce qui rend plus difficiles les contacts entre Suma et la cour). À partir de ce moment-là, l'écoulement du temps ralentit et l'entrée dans l'hiver aidant, la vie devient de plus en plus mélancolique et solitaire. C'est dans ce contexte que sont introduits des flash-back narratifs, dont les citations des poèmes de Michizane, qui éveillent chez le Genji le souvenir des banquets à la cour, sont un exemple. Mais il est un autre point plus intéressant encore : les retours sur le passé sont la source de rencontres avec de nouveaux personnages.

Autrement dit, il a fallu attendre que les contacts épistolaires avec la capitale cessent et que passe l'automne pour que le petit groupe d'hommes installé à Suma noue de nouveaux contacts, directs ou indirects, avec des personnages qui, eux, ne viennent pas de la capitale.

Le premier de ces personnages fait partie de la suite du Gouverneur général délégué de Dazai, de retour à la capitale et qui, chemin faisant, passe au large de Suma. Il s'agit de la fille de ce gouverneur, la "demoiselle de Gosechi », qui échange avec le héros des poèmes $^{26}$. Il avait été fait mention une fois de la jeune fille, au chapitre précédent, Hana chiru sato (Le séjour où fleurs au vent se dispersent). À travers cette rencontre, une nouvelle brèche s'ouvre ainsi en direction du passé.

38 Arrive l'hiver. Les échanges épistolaires sont à présent totalement interrompus (sous la pression de la dame du Kokiden en colère) ce qui inspire au Genji deux poèmes adressés à lui-même et dans lesquels il dit toute sa mélancolie. Suit alors immédiatement une scène avec le personnage du religieux d'Akashi (Akashi no nyūdō) qui expose à son épouse son projet de donner leur fille au Genji. Pour le lecteur, ce passage doit lui rappeler Waka-murasaki où il avait déjà été question de la famille d'Akashi et des ambitieuses intentions matrimoniales du religieux pour sa fille ${ }^{27}$. Dans Suma, la mère de

Cipango, Hors-série | 2008 
la jeune fille est opposée à l'idée de son époux. Elle invoque la faute commise par le Genji à l'égard d'une épouse impériale (Oborozukiyo). Le plus intéressant pour notre propos est la réponse du religieux :

Tomber en disgrâce, en Morokoshi [la Chine] aussi bien qu'en notre Empire, est pour un homme aussi éminent, qui en toute chose se distingue des autres, un accident inévitable. Qui est-il, ce Seigneur, le savez-vous seulement? [Sa mère], la défunte Dame de la Chambre était la fille de mon oncle le Grand Conseiller Inspecteur Général. Elle avait acquis un renom si grand que, lorsqu'on la mit au service du Palais, le Souverain lui accorda la toute première place dans ses faveurs, si bien que, accablée par la jalousie de ses rivales, elle en mourut, mais, par bonheur, elle nous avait laissé ce Prince. Une femme doit toujours placer haut ses ambitions. Ce n'est pas parce qu'elle vit ainsi à la campagne qu'il dédaignera nécessairement notre fille, disait-il. ${ }^{28}$

罪に当たることは、唐土にもわが朝廷にも、かく世にすぐれ、何ごとにも人に ことになりぬる人のかならずあることなり。いかにものしたまふ君ぞ。故母御 息所は、おのがをぢにものしたまひし按察大納言の御むすめなり。いと警策な る名をとりて、宮仕に出だしたまへりしに、国王すぐれて時めかしたまふこと 並びなかりけるほどに、人のそねみ重くて亡せたまひにしかど、この君のとま りたまへる、いとめでたしかし。女は心高くつかふ心゙きものなり。おのれかか る田舎人なりとて、思し亲てじ

Aux yeux d'Akashi no nyūdō, le «crime » du Genji doit plutôt être compris comme la preuve de sa personnalité exceptionnelle, qui ne peut se couler dans le moule d'une existence ordinaire. Mais ce passage révèle aussi les liens biologiques du Genji avec la famille d'Akashi, ce qui fait remonter le lecteur jusqu'au début du roman, au chapitre Kiritsubo (Le clos du Paulownia) et éclaire le personnage d'une nouvelle dimension. Cette conversation entre le religieux et son épouse forme une scène à elle seule, dont la teneur ne sera portée à la connaissance du principal intéressé que bien plus tard. Mais, pour le lecteur, l'ample flash-back narratif qu'elle induit est à l'origine d'une modification de la nature même du monde dans lequel évolue le Genji, dans la mesure où elle introduit de nouveaux liens familiaux, même si ce personnage lui-même ne les connaît pas encore. On notera enfin que la première mention de la famille d'Akashi apparaissait dans le même chapitre que le rêve annonçant l'exil à Suma. Comme si les graines semées au chapitre Waka-murasaki portaient leur fruit.

Les deux passages que nous venons de citer, celui du Gouverneur délégué de Dazai et celui de la famille d'Akashi, sont à l'origine d'une ouverture non seulement du cadre temporel, mais aussi du cadre spatial. Avec ces deux ensembles de personnages s'exerce en effet une nouvelle influence sur le Suma du Genji qui, cette fois-ci, ne provient plus de la capitale, mais des provinces situées plus à l'Ouest. Une précision géographique s'impose. Les côtes sur lesquelles le prince s'est retiré se trouvent dans la province de Settsu qui marque la limite occidentale de la région dite du Kinai 畿内. Or le Kinai est formé des cinq provinces à proximité immédiate de la cité de Heian, dont elles se trouvent sous l'emprise directe. Suma, quoique situé à l'extrémité occidentale de cette région, est donc encore placé dans la sphère d'influence de la cour. Akashi appartient en revanche à la province de Harima qui, d'un point de vue administratif, se trouve en dehors de cette région et est donc, de fait, dans le territoire dénommée le Kigai 畿外 par opposition au Kinai. Au chapitre Suma, il s'avère que le franchissement de cette frontière très marquée entre les provinces de Settsu et de Harima ne s'accomplit qu'après la rupture totale des liens avec les gens de la capitale. Les provinces occidentales, par opposition à la cour qui se trouve à l'Est, deviennent alors une nouvelle source d'influence qui fait progresser le récit. Puis, dans un second temps, une fois que ces nouveaux liens ont été racontés, le récit renoue avec la cour sous l'espèce 
de la venue de Tō no Chūjo ${ }^{29}$, une journée de printemps, en un passage d'une très grande beauté, profondément émouvant.

41 En résumé, les scènes automnales marquent une rupture à partir de laquelle de nouveaux territoires, clairement distincts de la cour, agissent ponctuellement ou durablement sur le destin du Genji. Or on peut considérer que les scènes lyriques ont préparé l'intervention de ces forces agissantes. En effet, au moment précis où les personnages et le lecteur sont prêts à sombrer dans le désespoir et la mélancolie, sourdent du plus profond de l'histoire, tout doucement, les prémices d'une évolution spatiale et temporelle. Loin de s'opposer à la progression du récit, comme on pourrait le supposer, le lyrisme lui impulse ainsi un nouvel élan. Les scènes qui abondent en poèmes paraissaient à première vue former un tout à elles seules, alors qu'après avoir submergé le lecteur d'une forte charge émotionnelle, elles forment l'écrin sur lequel se révèlent, et ce avec d'autant plus d'acuité, le destin du Genji et les aspects les plus secrets de ce roman.

\section{Conclusion}

La fin de Suma et le début d'Akashi sont traversés de soubresauts : le déchaînement des orages, l'apparition de l'esprit de l'empereur retiré Kiritsubo, l'intervention du dieu de Sumiyoshi pour accélérer la venue en bateau du religieux d'Akashi. Le dynamisme de ces scènes est unique dans tout le Genji monogatari et, qui plus est, les événements surnaturels (les échanges avec d'autres mondes) y sont particulièrement intenses. On peut y voir un lien avec l'histoire d'Umi sachi et Yama sachi, séquence mythique particulièrement adaptée au récit de chute et de renaissance du héros ${ }^{30}$. Seul ce mythe recelait l'énergie nécessaire pour faire exploser les références aux personnages historiques ayant connu un destin similaire à celui du Genji (une chute et une renaissance) et pour créer les conditions nécessaires à l'accession du héros à une splendeur inégalée. Comparé aux récits romanesques antérieurs comme le Taketori monogatari (Le Conte du coupeur de bambou), l'Utsuho monogatari (Le Roman de la Caverne) ou l'Ochikubo monogatari (Le Roman de la Chambre basse), le Roman du Genji a beaucoup emprunté aux récits mythiques. C'est d'ailleurs ce que l'empereur Ichijō remarquait déjà lorsqu'il disait de son auteur : "Cette personne a dû lire le Nihon gi [Nihon shoki] ", comme le rapporte Murasaki Shikibu dans son journal. Celle-ci avait certainement une conscience très nette de la faculté des mythes à fournir des descriptions, même simplement ébauchées, des hommes. S'engager sur la question des références aux mythes dans le Genji monogatari risquerait de nous entraîner fort loin. Ce qui me semble important pour notre propos, c'est de rappeler la précision avec laquelle les mythes observent les hommes, et combien aussi les descriptions, quoique sommaires, sont évocatrices et portent un vrai regard sur eux. Il est clair que ce mode d'expression est à l'opposé des analyses très fines des dispositions intérieures des personnages, mode d'expression que le Roman du Genji a poussé très loin. Ce sont pourtant ces deux formes d'expression, en apparence antagonistes qui, dans le chapitre Suma, se rejoignent admirablement. 


\section{NOTES}

1. Suma est situé dans la partie occidentale maritime du pays de Settsu (actuelle ville de Kōbe). La barrière, Suma no seki, qui constituait la frontière avec le pays de Harima, était connue comme un site éminemment poétique de la tradition littéraire classique. (NDT)

2. Rappelons que Fujitsubo (la dame du clos des Glycines) est l'épouse impériale que l'empereur Kiritsubo avait choisie pour sa ressemblance avec la dame d'atour Kiritsubo (la dame du clos du Paulownia), la mère du Genji, qui était décédée. Le Genji s'est épris de sa belle-mère pour la même raison et est parvenu à l'approcher. Le fils adultérin né de cette union est donc officiellement le fils de l'empereur et le frère cadet du Genji. (NDT)

3. Les extraits du Genji monogatari sont tous tirés de la collection «Shin Nihon koten bungaku zenshū » 新日本古典文学全集 de l'édition Shōgakukan (plus loin : SNKBZ), Abe Akio 阿部秋生, Akiyama Ken 秋山虔, Imai Gen.e 今井源衛 et Suzuki Hideo 鈴木日出男 (éd.), 1994-1998. Les traductions en français sont empruntées à René Sieffert, Le Dit du Genji, POF, 1988. SNKBZ, II, «Suma », p. 165-166. Traduction R. Sieffert, tome 1, Livre XII « Suma », p. 249.

4. SNKBZ, II, « Suma », p. 179. Traduction R. Sieffert, tome I, Livre XII « Suma », p. 256.

5. Un passage entre les deux extraits cités le dit explicitement: «Et parce qu'il n'avait plus ni rang ni titre, il mit une casaque sans dessin, fort seyante, tenue modeste qui ne le rendait que plus aimable. » SNKBZ II, p. 173, trad. R. Sieffert, tome 1, Livre XII « Suma », p. 252.

6. SNKBZ, II, p. 137-138. Trad. R. Sieffert, tome 1, Livre X « L'Arbre sacré », p. 236.

7. SNKBZ, I, p. 233-234. Trad. R. Sieffert, tome 1, Livre V « Jeune Grémil », p. 112. La traduction de R. Sieffert a été légèrement modifiée.

8. Rappelons que la dame du Kokiden est non seulement la mère de l'empereur régnant Suzaku, mais elle est aussi l'épouse principale de l'ancien empereur défunt Kiritusbo. Déjà, lorsque le Genji était tout enfant, l'intense affection de l'empereur à l'égard de la dame d'atour Kiritsubo, la mère du Genji, poussa la dame du Kokiden à voir en cette dernière une rivale. Sa jalousie est l'une des raisons du dépérissement, puis de la mort de la dame d'atour. Elle reporta ensuite son aversion sur Fujitsubo, après l'admission de celle-ci au palais. (NDT)

9. Cette liaison est la principale raison objective fondant le départ en exil du Genji. Le héros l'invoque d'ailleurs lui-même. Oborozukiyo est la sœur cadette de la dame du Kokiden, issue de la même mère. (NDT)

10. SNKBZ, II, p. 198-199. Traduction R. Sieffert modifiée en deux endroits, tome 1, Livre XII «Suma » p. 266-267.

11. Sauf indication contraire, les poèmes sont traduits par nos soins. (NDT)

12. SNKBZ, II, p. 187. Traduction R. Sieffert, tome 1, Livre XII « Suma », p. 260.

13. Ce poème fait partie des compositions les plus célèbres de Yukihira. (NDT)

14. Cet ouvrage anonyme porte un colophon daté de la $4^{\mathrm{e}}$ année de l'ère Shōwa 正和 soit 1315 . Il regroupe des commentaires critiques du Gyokuyō shū 玉葉集 (Anthologie des feuilles de jade de la poésie), quatorzième anthologie impériale achevée en 1312. Les commentaires sont signés par dix auteurs, mais il s'agit en fait de textes apocryphes. (NDT)

15. Fujiwara no Mitsutoshi (1203-1276), alias Shinkan, est l'un des compilateurs du Shoku kokin shū. (NDT)

16. Nihon kagaku taikei 日本歌学大系, tome 4, Kazama shobō 風間書房, 1980, p. 106.

17. SNKBZ, IV, p. 173-174. Trad. René Sieffert, tome 2, Livre XXXV «Jeunes herbes », p. 85. Dans ce passage, il est possible de comprendre de deux manières la première phrase de la séquence en prose : dans le premier cas, choisi ici par le traducteur, c'est Murasaki qui évoque le matin de neige dans son poème; dans le deuxième cas, c'est le narrateur qui remarque que le poème évoque le matin de neige. (NDT) 
18. Le Fukuro zōshi (Le cahier aux pages mises en double) est un traité de poésie composé par Fujiwara no Kiyosuke (1104-1177) et achevé vers 1157. (NDT)

19. Fukuro zōshi, Fujioka Tadaharu 藤岡忠美 (éd), coll. «Shin Nihon koten bungaku taikei », Iwanami shoten, 1995, p. 118.

20. SNKBZ II, p. 202-203. Traduction R. Sieffert, avec modifications, tome 1, Livre XII « Suma ", p. 268-269.

21. Nous remercions Valérie Lavoix pour ses précisions sur l'interprétation du poème. (NDT)

22. Cf. Fujiwara Katsumi 藤原克己, «Genji monogatari to chūgoku bungaku » (Le Roman du Genji et la littérature chinoise) 源氏物語と中国文学, Shin-Genji monogatari hikkei 新源氏物語必携, Tōkyō, Gakutōsha, 1997.

23. En 900 (Shōtai, 3), lors d'un banquet qui eut lieu le soir du $10^{\mathrm{e}}$ jour de la $9^{\mathrm{e}}$ lune, l'empereur Daigo offrit à Michizane, qui était alors ministre de Droite, un vêtement en récompense d'un poème composé sur le thème de la « Mélancolie automnale ». Le poème de Michizane composé un an plus tard dans l'exil renvoie à cet heureux événement. Si cet épisode réel est bien connu, en revanche, aucun passage du Roman du Genji, dans les chapitres précédents Suma, ne raconte de scène similaire. (NDT)

24. Il s'agit de la fin de Suma et du début du chapitre suivant Akashi. Le Genji se rend sur la grève pour procéder à une cérémonie de purification au cours de laquelle il se fait surprendre par l'orage qui s'intensifie, ravage tout et semble libérer les éléments surnaturels. Ces scènes peuvent être rapprochées d'une des catastrophes qui eurent lieu après la mort de Michizane: la destruction du Palais lors d'un orage attribué au courroux de l'esprit de Michizane. (NDT)

25. Au début du chapitre Akashi, peu après la scène de l'orage, le Genji voit en rêve son père. La description qui y est faite rappelle l'empereur Daigo qui, selon une légende rapportée par le Kitano engi 北野縁起, serait tombé en enfer pour avoir commis cinq crimes de son vivant. Ce rapprochement entre Kiritsubo et Daigo est d'autant plus plausible que les descriptions de l'empereur du roman, dans les chapitres précédents, rappelaient déjà Daigo. Genji monogatari, Ishida Jōji 石田穣二 et Shimizu Yoshiko 清水好子 (éd.), Shinchō Nihon koten shūsei 新潮日本古 典集成, II, Tōkyō, Shinchōsha 新潮社, 1977, p. 265, note 10. (NDT)

26. Voir la traduction de R. Sieffert, tome 1, Livre V « Suma », p. 269-270. (NDT)

27. Cette scène apparaît au début de Waka-murasaki (traduction R. Sieffert, tome 1, Livre V «Jeune Grémil », p. 95-96). (NDT)

28. SNKBZ, vol. II, p. 211. Traduction R. Sieffert, tome 1, Livre XII « Suma », p. 274.

29. Le meilleur ami et rival du Genji qui est également le frère d'Aoi, sa première femme défunte.

30. Le Kakaishō est le premier ouvrage à avoir fait ce rapprochement. Pour une analyse détaillée de cette question, on se réfèrera à : Ishikawa Tōru 石川徹, «Hikaru Genji Suma rutaku no kōsō no gensen » 光源氏須磨流謫の構想の源泉 (Les sources du récit de relégation à Suma du Genji), Heian jidai monogatari bungaku ron 平安時代物語文学論, Kasama shoin 笠間書院, 1979.

\section{RÉSUMÉS}

Étude de Suma, chapitre singulier par son lyrisme et l'importance accordée au destin, qui présente le prince Genji en exil pour y fuir deux crimes.

Study on "Suma", a chapter with particular lyricism from the Genji monogatari where fate plays an important role. Prince Genji has gone into voluntary exile because of two crimes. 
INDEX

Thèmes : littérature

キーワード : yūzai 有罪, bōmei 亡命, jojōshi 抒情詩, shinwa 神話, Genji monogatari 源氏物語, Murasaki Shikibu 紫式部 (v. 973-v. 1014 ou 1025), shi 詩, sanbun 散文, Heian jidai 平安時代 (794-1185), bungaku 文学

Mots-clés : culpabilité, exil, Genji, Genji monogatari, lyrisme (littérature), récits mythiques, écriture, Dit du Genji, Murasaki Shikibu (v. 973-v. 1014 ou 1025), poésie, prose

Index géographique : Suma

Keywords : Exil, Genji, Genji monogatari, Guilt, Heian, Literature, Suma, Murasaki Shikibu (v. 973-v. 1014 or 1025), Tale of Genji

Index chronologique : Heian 